\title{
Genetics and tailored therapy in cardiovascular disease
}

\author{
P. A. Doevendans $\cdot$ F. W. Asselbergs
}

Published online: 10 December 2011

(C) The Author(s) 2011. This article is published with open access at Springerlink.com

Can we today apply genetics to individual patients and tailor therapy based on genetic profile to improve pharmacodynamics and kinetics [1]? This is an interesting question especially for the treatment of hypertension as substantial heterogeneity in efficacy exists in response to drug therapy. Individualised medicine may guide physicians in their choice instead of the old-fashioned trial-and-error strategy to find the perfect cocktail of antihypertensive drugs. In addition, tailored therapy may lead to fewer adverse drug reactions and eventually to a lower burden on health care costs [2]. Although the department of cardiology of the University Medical Center Utrecht is committed to the integration of genetics into clinical medicine, we do not determine a genetic profile in patients on a routine basis [3]. Especially not before prescribing a drug in the clinic or in the outpatient department. But maybe it is time to change our attitude and integrate genetics into daily clinical practice. Nowadays it is technically feasible to determine several single nucleotide polymorphisms (SNPs) within 1 hour at relatively low costs in the outpatient office without the need for specialised laboratory facilities $[4,5]$.

In their review article in this issue of the Netherlands Heart Journal, Brugts et al. suggest that we should adjust

\footnotetext{
P. A. Doevendans · F. W. Asselbergs

Department of Cardiology, Division Heart \& Lungs, University Medical Center Utrecht,

Utrecht, the Netherlands

F. W. Asselbergs $(\triangle)$

Room E03.511, P.O. Box 85500, 3508 GA, Utrecht, the Netherlands

e-mail: F.W.Asselbergs@umcutrecht.nl
}

our current practice. The review contains a broad description of the role of ACE inhibition in the treatment of patients with atherosclerosis [6]. The paper is very well written and comprises part of the outstanding work delivered by the Rotterdam group and collected in the thesis successfully defended by Dr Brugts. Here the focus is on genetic analysis. In a substudy of the well-described EUROPA trial with 9454 patients suffering from stable coronary artery disease, a genetic analysis was performed (PERGENE study) [7]. After multivariate analysis 3 SNPs were reported to be related to the effect of perindopril on cardiovascular events. Patients with 3 or more unfavourable alleles were considered to be nonresponders based on numbers of events. This paper suggests to decide on the treatment with ACE inhibitors based on genetic profiling. The authors claim that one out of 4 patients should not be treated with ACE inhibitors to reduce the cost of treatment and to improve drug efficacy [8].

The question is whether there is now sufficient proof that genetic testing is important for decision-making and if so can we apply the statistics of the large population to one individual. Several issues with respect to the PERGENE study catch the eye. Looking at figure 5 in their article, it is crucial to realise that the most important variation is in the placebo group and not so much in the treated group [6]. The variation in the ACE inhibitor treated group varies from 8.0, 7.5 to 9.4 and is very modest. The real variation is found in the placebo group. Here the absolute risk moves from 10.2 to 11.1 and 7.7. Basically, the PERGENE study does not say much about the effect of ACE inhibitor therapy, but more on basic risk without additional treatment to develop events. If the risk is modest ACE inhibition does not add much. In addition, as the authors stated, sample size is an issue in 
genetic research and replication is essential, especially in subgroup analyses. Unfortunately, no similar randomised trial to EUROPA with available DNA samples exists at this point, thereby eliminating the possibility to replicate or increase the sample size. Another issue is the coverage of the genes by tagSNPs. It is not likely that the selected SNPs are biologically relevant considering their high frequency, but serve as proxy for the functional variant. Those variants are rare and are not well covered by traditional genome-wide association studies. Resequencing of all genes within the RAAS and bradykinin system will be needed to detect functional variants explaining interindividual variability in drug response. All clinicians are aware of the difficulty in translating statistically significant epidemiological and also genetic data to the treatment of one individual [9]. This is especially true for subtle changes in risk related to a few SNPs. Based on epidemiology, oestrogen suppletion in postmenopausal women appeared a logical next step in the 1990s [10]. Clinical trials showed the downside of such an intervention. Therefore, randomised clinical trials (RCT) randomising treatment based on genetic profiling are necessary to provide a definitive answer whether tailored therapy will improve outcome. Trials using genotype-guided therapy, such as RAPID GENE, are already underway for the treatment of ACS patients. In this trial the ReAssessment of Anti-Platelet Therapy Using an InDividualized Strategy Based on GENetic Evaluation (RAPID GENE) will be performed to identify CYP2C19*2 carriers. Carriers will be treated with prasugrel. The study has been completed and the results are expected soon.

In conclusion, pharmacogenetics are around the corner, but need RCTs and improved bioinformatics before genetic analysis will be crucial in every cardiology office to advice our patients.
Open Access This article is distributed under the terms of the Creative Commons Attribution Noncommercial License which permits any noncommercial use, distribution, and reproduction in any medium, provided the original author(s) and source are credited.

\section{References}

1. Doevendans PA. Unravelling the pathophysiology of heart failure through human genomics. Eur J Clin Invest. 2001;31:378-9.

2. Ma Q, Lu AY. Pharmacogenetics, pharmacogenomics, and individualized medicine. Pharmacol Rev. 2011;63:437-59.

3. Baars H, van der Smagt J, Doevendans P. Clinical cardiogenetics. London: Springer; 2011.

4. Harmsze AM, van Werkum JW, Ten Berg JM, et al. Cyp2c19*2 and cyp $2 \mathrm{c} 9 * 3$ alleles are associated with stent thrombosis: A case-control study. Eur Heart J. 2010;31:3046-53.

5. Schimmenti LA, Warman B, Schleiss MR, et al. Evaluation of newborn screening bloodspot-based genetic testing as second tier screen for bedside newborn hearing screening. Genet Med. 2011.

6. Brugts JJ, de Maat MPM, Danser AHJ, Boersma E, Simoons ML. Individualised therapy of ACE inhibitors in stable coronary artery disease: overview of the primary results of the PERindopril GENEtic association study. Neth Heart J. 2012;20:xx-xx.

7. Fox KM. Efficacy of perindopril in reduction of cardiovascular events among patients with stable coronary artery disease: randomised, double-blind, placebo-controlled, multicentre trial (the Europa study). Lancet. 2003;362:782-8.

8. Brugts JJ, de Maat MP, Boersma E, et al. The rationale and design of the perindopril genetic association study (pergene): a pharmacogenetic analysis of angiotensin-converting enzyme inhibitor therapy in patients with stable coronary artery disease. Cardiovasc Drugs Ther. 2009;23:171-81.

9. Bentley JP, Asselbergs FW, Coffey CS, et al. Cardiovascular risk associated with interactions among polymorphisms in genes from the renin-angiotensin, bradykinin, and fibrinolytic systems. PLoS One. 2010;5:e12757.

10. Hulley S, Grady D, Bush T, et al. Randomized trial of estrogen plus progestin for secondary prevention of coronary heart disease in postmenopausal women. Heart and estrogen/progestin replacement study (HERS) research group. JAMA. 1998;280:605-13. 